\title{
Brain Auditory Activation Measured by Near-Infrared Spectroscopy (NIRS) in Neonates
}

\author{
PATRIZIA ZARAMELLA, FEDERICA FREATO, ANGELA AMIGONI, SABRINA SALVADORI, \\ PAOLA MARANGONI, AGNESE SUPPJEI, BARBARA SCHIAVO, LINO CHIANDETTI
}

Department of Paediatrics, University of Padua, Via Giustiniani, 3, IT-35128 Padova, Italy

ABSTRACT

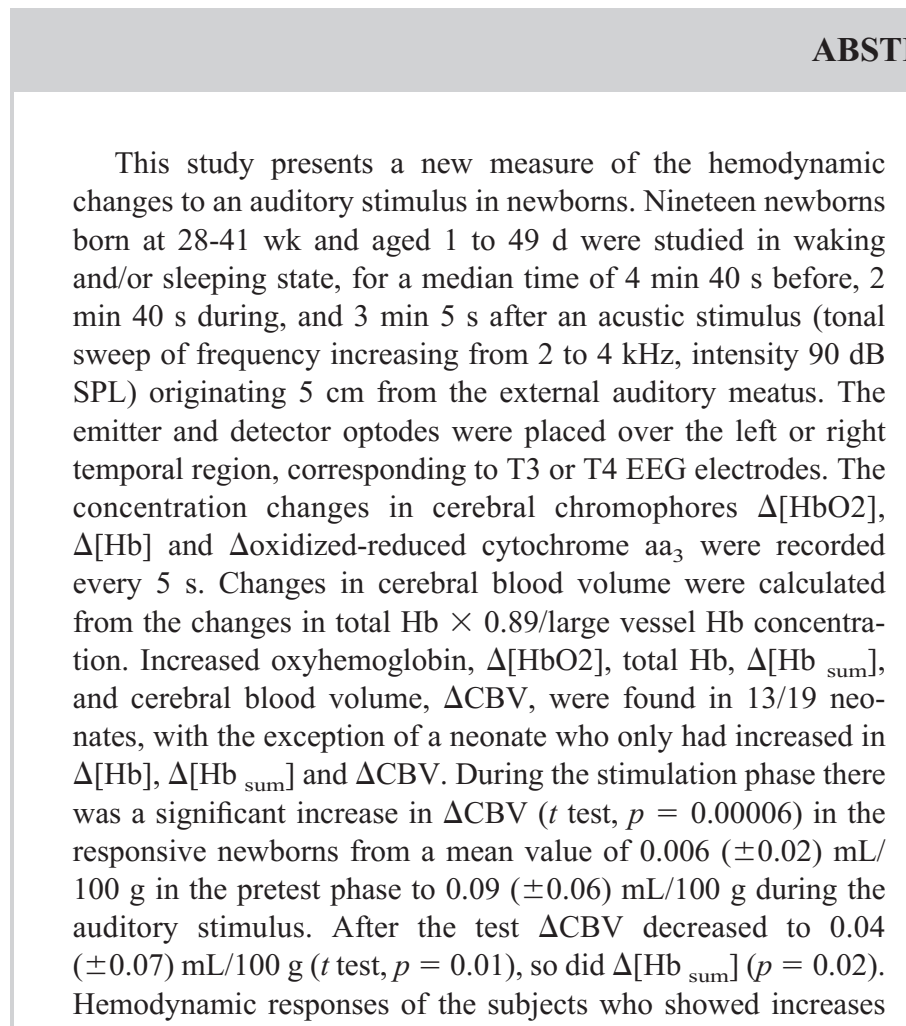

in $\Delta[\mathrm{Hb}$ sum $]$ and $\Delta\left[\mathrm{HbO}_{2}\right]$ were analyzed to study the $\Delta[\mathrm{Hb}]$. The responder subjects could be classified into two groups according to $\Delta[\mathrm{Hb}]$ changes: $8 / 13(61.5 \%)$ showed an increase of $\Delta[\mathrm{Hb}]$ (pattern A), while 5/13 $(38.4 \%)$ showed a decrease (pattern B) ( $t$ test, $p=0.03$ ). These two patterns did not show differences related to $\Delta\left[\mathrm{HbO}_{2}\right]$ and $\Delta[\mathrm{Hb}$ sum $]$. The $\Delta \mathrm{CBV}$ changes in nonresponders presented a decrease during the test phase ( $t$ test, $p=0.04$ ). CBV did not return to pretest values, suggesting a fronto-temporal brain pathway for storing unusual sounds. The increase in CBV followed the local increase in oxyhemoglobin and total $\mathrm{Hb}$ concentrations due to a greater use of oxygen in the homolateral temporal cortex of the newborns.

(Pediatr Res 49: 213-219, 2001)
Abbreviations:
$\Delta[\mathbf{H b O 2}]$, oxyhemoglobin change
$\Delta[\mathbf{H b}]$, deoxyhemoglobin change
$\Delta[\mathbf{C t O x}]$, cytochrome oxidase change
$\Delta\left[\mathbf{H b}_{\text {sum }}\right]$, total $\mathrm{Hb}$ change
$\triangle \mathrm{CBV}$, cerebral blood volume change
BAEP, brainstem auditory evoked potentials
NIRS, near-infrared transmission spectroscopy

Near-infrared transmission spectroscopy (NIRS) through tissue is made possible by the transparency of biologic tissue to light in the near-infrared region $(750-1000 \mathrm{~nm})$. The noninvasive nature of the technique and the portability of the device, combined with the relative transparency of the neonatal head, explain the early applications of the machine in neonatal intensive care units, to the observation of hemodynamic brain responses. Our study presents a method for applying NIRS to the testing of central auditory response in newborns by using an acustic stimulus, a tonal sweep with a frequency increasing from 2 to $4 \mathrm{KHz}$. The incident near-infrared light from the transmitting optode is scattered through the tissues, and the reflected light is read by a receiving optode. The amount of the

Received May 5, 1999; accepted September 1, 2000.

Patrizia Zaramella, M.D., Department of Paediatrics, Neonatal Intensive Care Unit, University of Padua, Via Giustiniani, 3, IT-35128 Padova, Italy. light that a compound absorbs is dependent upon the wavelength of the incident light upon it, and is described by the spectrum of a single compound. Brain absorption of the light is due to the main cerebral chromophores, oxyhemoglobin $\left(\mathrm{HbO}_{2}\right)$, deoxyhemoglobin $(\mathrm{Hb})$, and oxidized cytochrome oxidase (CtOx) and is determined by the oxygenation status of the compound. Through NIRS we measured the loss of the intensity due to absorption of the incident photons by these solutes; this loss or attenuation is usually measured in units of OD (OD) and can be calculated using the Beer-Lambert law. For an absorbing compound dissolved in a nonabsorbing medium, the attenuation (A) is proportional to the concentration of the compound in the solution (c), the specific extinction coefficient of the compound $(\alpha)$ and the optical path length (d). The loss of light intensity (attenuation), $\mathrm{A}=\lg \left[\mathrm{I}_{0} / \mathrm{I}\right]=\alpha \mathrm{c} \mathrm{d}$. (A = attenuation measured in OD; $\mathrm{I}_{\mathrm{o}}=$ the light intensity incident on the medium; I = the light intensity transmitted through the 
medium; $\alpha=$ specific extinction coefficient of the chromophore measured in $\mu \mathrm{mol}^{-1} \cdot \mathrm{L}^{-1} \cdot \mathrm{cm}^{-1} ; \mathrm{c}=$ the concentration of the chromophore in the solution measured in $\mu \mathrm{mol} \cdot \mathrm{L}^{-1} ; \mathrm{d}=$ distance between the points where the light enters and leaves the solution measured in centimeters). It has been estimated that with sensitive instrumentation a NIR light penetration up to $8 \mathrm{~cm}$ is possible in a biologic tissue from the sending to the receiving points (1). The scattering effect of the light increases the attenuation at a single sample point above that to be expected from absorption alone. When the light is absorbed the energy of photons is lost as thermal energy throughout the absorber. Because the photon collisions are elastic, no energy is lost when NIR light is scattered in tissue, and the photons change direction. In the brain tissue there are known to be some microscopic and macroscopic boundaries (i.e. cell membranes, bone, and large blood vessels) which can increase scattering. The scattering effect of tissue explains why the optical pathlength is much greater than the geometrical distance (d) between the sites of light entry and exit. This true optical distance has been named as differential pathlength (DP) and the scaling factor as the differential pathlength factor (DPF). The absolute concentration of a chromophore is unknown, and the measurements are expressed as absolute concentration changes from an arbitrary zero made at the beginning of the measurements. Using this technique the changes in tissue oxygenation can be noninvasively monitored. This relative change can be used to calculate the absolute changes in cerebral blood flow and cerebral blood volume through the increase of a known amount of $\mathrm{FiO}_{2}$. Experimental data on the neonatal head demonstrate that contamination of the light signals due to transmission through skin and bone is minimal when the inter-optode spacing is more than $3 \mathrm{~cm}$ (2). The fibers for emitting NIR light are optical fibers terminating as small cylindrical optodes containing prisms that direct the light normally onto the surface of the tissue because the highly scattering brain medium is scanned between the two optodes. The inter-optode distance consequently means the inter-optode spacing, and this distance is the straight line, rather than the curve, through the two points. This is due to the light's diffusion in the brain, which acts as an isotropic source (3), even though the angle of the emission-detection lines is less than $180^{\circ}$.
NIRS has been used to demonstrate evoked changes in regional hemodynamics in adults and in infants after sensorineural stimulation (Table 1) (4-12). The increase in cerebral blood volume (CBV) follows the increase in $\mathrm{HbO}_{2}$ (oxyhemoglobin) and in $\mathrm{Hb}$ (deoxyhemoglobin) seen in the occipital region upon visual stimulation. Changes in both $\mathrm{HbO}_{2}$ and in $\mathrm{Hb}$ are measured from an arbitrary zero, and their sum is equal to total $\mathrm{Hb}$, which is related to changes in CBV (13). Ohnishi et al. (9) first measured the changes evoked in the hemodynamics of the auditory cortex with NIRS and magnetoencephalography in an adult subject. They found significant increases of the total $\mathrm{Hb}$ and deoxyHb in the brain region at a depth of $20-30 \mathrm{~mm}$ corresponding to the auditory cortex of the MEG topogram. Increased oxyhemoglobin and total $\mathrm{Hb}$ induced by auditory (music) stimulation were found in the bilateral frontal lobes of the newborns studied recently by Sakatani et al. (12). They described two patterns with and without an increase of $\mathrm{Hb}$ (deoxyhemoglobin). To study the auditory function of the newborns, we performed an NIRS application in monitoring the changes of oxygenation as well of cerebral blood volume in the temporal cortex of 19 preterm and term neonates stimulated with a tonal sweep sound with a frequency increasing from 2 to $4 \mathrm{KHz}$.

\section{SUBJECTS AND METHODS}

Nineteen newborns aged 1 to $49 \mathrm{~d}$ (median 15 d) were studied. They were born between 1998 and 2000 and were admitted to the Neonatal Unit at the Pediatric Department of Padua University at birth. The mean gestational age was $32 \mathrm{wk}$ (range 28 to $41 \mathrm{wk}$ ) and the averaged birth weight was 1936.7 $\mathrm{g}$ (range 990 to $4500 \mathrm{~g}$ ). The diagnosis on admission was jaline membrane disease (5 neonates), congenital heart disease (2 neonates), twin pregnancy and/or apneic spells, with or without metabolic problems (16 neonates), asphyxia (1 neonate). Six newborns were incubated and ventilated at birth for a time ranging between 1-7 d, and the median hospital stay at the NICU was $21 \mathrm{~d}$ (range 10 to $57 \mathrm{~d}$ ). Ten patients were treated with oxygen therapy for a mean time of $5 \mathrm{~d}$ (range 1 to $8 \mathrm{~d}$ ). All infants, except one neonate with subependymal hemorrhage, appeared normal on cranial ultrasound or had transient periventricular echodense areas at the time of study (HDI $3000 \mathrm{CV}$,

Table 1. Sensorineural stimulation and brain evoked activation NIRS studies

\begin{tabular}{|c|c|c|c|c|c|c|c|}
\hline Study & Stimulus & Localization of probes & $\begin{array}{l}\text { Stimulus/ } \\
\text { rest } \\
\text { duration }\end{array}$ & $\begin{array}{c}\text { Mean } \\
\Delta\left[\mathrm{Hb} \mathrm{O}_{2}\right](\mathrm{SD}) \\
(\mu \mathrm{mol} / \mathrm{L})\end{array}$ & $\begin{array}{c}\text { Mean } \\
\Delta\left[\mathrm{Hb}_{\text {sum }}\right](\mathrm{SD}) \\
(\mu \mathrm{mol} / \mathrm{L})\end{array}$ & $\begin{array}{c}\text { Mean } \\
\Delta\left[\mathrm{Hb}_{\text {sum }}\right](\mathrm{SD}) \\
(\mu \mathrm{mol} / \mathrm{L})\end{array}$ & $\begin{array}{c}\text { Mean } \\
\Delta \mathrm{CBV}(\mathrm{SD}) \\
\mathrm{ml} / 100 \mathrm{~g}\end{array}$ \\
\hline Villringer A, et al., 19934 & Flashlight & Right occipital & $1 \mathrm{~min}$ & $+1.16(0.26)$ & $-0.67(0.51)$ & $+0.49(0.74)$ & \\
\hline Villringer A, et al., 19934 & Picture observation & Right occipital & $1 \mathrm{~min}$ & $+2.78(2.54)$ & $-2.57(0.61)$ & $+0.18(2.9)$ & \\
\hline Hoshi Y, et al., 19935 & Flashlight & Occipital & $2-3 \mathrm{~min}$ & + & + & + & \\
\hline Hoshi Y, et al., 19935 & Auditory (music) & Temporal & $2-3 \mathrm{~min}$ & + & + & + & \\
\hline Kato T, et al., 19936 & Flashlight & Besides inion & $10 / 10 \mathrm{~min}$ & $3.4(2.46)$ & $+/ 0$ & & \\
\hline Meek JH, et al., 1995, 1998 & Moving colored disks & Below and beside inion & $30 / 30 \mathrm{~s}$ & $+0.54(0.14)$ & $+0.06(0.08)$ & $+0.61(0.21)$ & $+0.04(0.01)$ \\
\hline Ohnishi M, et al., 19979 & Tone burst sine wave & Left temporal lobe & $50 \mathrm{~ms}$ & & + & + & \\
\hline Heekeren HR, et al., 199910 & Visual stimulation & Occipital cortex & $10 / 30 \mathrm{~s}$ & $+0.12(0.03)$ & $-0.10(0.01)$ & & \\
\hline Bartocci M, et al., 199911 & Olphactory stimulation & Orbital-frontal bilateral & $10 \mathrm{~s}$ & - & $=$ & & \\
\hline Sakatani K, et al., 199912 & Auditory (piano music) & Frontal bilateral & $10 \mathrm{~min}$ & + & $+1-$ & + & \\
\hline Present study & Auditory (sweep) & Temporal unilateral & $2 \min 40 \mathrm{~s}$ & $+1.08(1.21)$ & $+0.53(1.31)$ & $+1.62(1.08)$ & $+0.09(0.06)$ \\
\hline
\end{tabular}

+ , increased; -, decreased; $+/$, increased or decreased; $=$, not increased and not decreased. 
ATL, USA). All the neonates were in good condition, and normal care was provided at the time of the examination. Clinical details are given in Table 2. The emission and detection probes of the Near-Infrared Oxygenation Monitor (NIRO 300 Hamamatsu Photonics KK, Japan) were placed on the neonates' temporal area (inter-optode distance $3.5 \mathrm{~cm}$ ) to study the cerebral cortex and adjacent subcortical white matter in one of the temporal auditory brain sites. A personal computer converted absorption changes at each wavelength, recorded every $5 \mathrm{~s}$, into relative concentration changes in cerebral chromophores: $\Delta\left[\mathrm{HbO}_{2}\right], \Delta[\mathrm{Hb}], \Delta$ oxidized-reduced cytochrome $\mathrm{aa}_{3}$. The changes were expressed in micromol/L, and the optical pathlength was calculated by multiplying the interoptode distance by 3.9 DPF (14). The sum of changes in oxyhemoglobin and deoxyhemoglobin enabled the calculation of the changes in total $\mathrm{Hb}, \Delta\left[\mathrm{Hb}_{\text {sum }}\right]$; because the hematocrit was constant, changes in CBV ( $\mathrm{mL} / 100 \mathrm{~g}$ of brain tissue) were calculated from the changes in total $\mathrm{Hb} \times 0.89 / \mathrm{Hb}$ concentration in $\mathrm{g} / \mathrm{dL}$, corresponding to a large-vessel $\mathrm{Hb}$ concentration $(13,15)$. Using double-faced adhesive tape (bordering the external ear, i.e. corresponding to a $\mathrm{T} 3$ or $\mathrm{T} 4$ placement of the 10/20 EEG system), the probe holders were placed over the left or right temporal region corresponding to the primary auditory cortex. To prevent ambient light from reaching the optodes, a dark felt covered the neonate's head. The neonates were studied while they were in sleeping and/or in waking states, in an interval covering a median time of 4 min $40 \mathrm{~s}$ before, $2 \mathrm{~min}$ $40 \mathrm{~s}$ during and $3 \mathrm{~min} 5 \mathrm{~s}$ after the hearing stimulus. Audiometric sound stimulation was a tonal sweep with a frequency increasing from 2 to $4 \mathrm{kHz}$, intensity $90 \mathrm{~dB}$ SPL (Electrical Acoustics Constructions, EAC, Milan Mercury) applied $5 \mathrm{~cm}$ away from the external auditory meatus. The reasons for choosing this particular auditory stimulus were to prompt more attention to a train of briefly repeated high-energy sounds rather than to a continuous sound of costant energy $(16,17)$. Movement artifacts were seen during the study period, but we ruled out any influence of the consequent sharp spikes on the chromophores by excluding the traces containing the spikes in relation to a cytochrome $\mathrm{aa}_{3}$ threshold level between 0.2 and -0.2 (18). On excluding the changes in chromophores related to the artifact movements, the evaluation of the test-phase was calculated in a time ranging from 80 (16 changes) to 430 (86 changes) seconds. Brainstem auditory evoked potentials (BAEPs, Multibasis System 2791, Italy) were performed in the newborns at an age spanning from $12 \mathrm{~d}$ to 9 mo. Student's $t$ test was performed to compare the averaged NIRS parameters in relation to the studied phases. Ethical approval for the study from the local ethics committee and informed consent from parents were obtained.

\section{RESULTS}

The concentration changes in $\Delta\left[\mathrm{HbO}_{2}\right], \Delta[\mathrm{Hb}], \Delta[\mathrm{Hb}$ sum $]$, and $\Delta[\mathrm{CtOx}]$ are in micromol/L; CBV is given in $\mathrm{mL} / 100 \mathrm{~g}$ of brain tissue. The baseline or pretest values represent the chromophore changes and CBV at the normal/basal condition of the neonates. We considered the averaged changes and the CBV changes in the basal, stimulus, and poststimulus phases. "Zero

Table 2. Clinical details of neonates

\begin{tabular}{|c|c|c|c|c|c|c|c|}
\hline Neonate & Delivery & $\mathrm{GA}^{*}$ & $\begin{array}{l}\text { Apgar } \\
\text { score }\end{array}$ & $\mathrm{BW} \dagger$ & $\begin{array}{l}\text { Age at NIRS } \\
\text { (days) }\end{array}$ & Cranial ultrasound & Admission diagnosis \\
\hline 1 & CS & 34 & $9,9,10$ & 3020 & 6 & Periventricular echodensities & HMD $\S$ \\
\hline 2 & $\mathrm{CS}$ & 32 & $9,10,10$ & 1990 & 1 & Normal & Twin, hypoglycemia \\
\hline 4 & CS & 28 & $9,10,10$ & 990 & 30 & Normal & $\begin{array}{l}\text { Hyperbilirubinemia, transient } \\
\text { myocardial ischemia }\end{array}$ \\
\hline 5 & $\mathrm{CS}$ & 29 & $5,7,10$ & 1450 & 20 & Normal & Asphyxia, hyperbilirubinemia \\
\hline 8 & $\mathrm{CS}$ & 31 & $7,9,10$ & 1630 & 30 & Normal & $\begin{array}{l}\text { HMD, patent ductus arteriosus, } \\
\text { hyperbilirubinemia }\end{array}$ \\
\hline 9 & vaginal & 41 & $8,9,10$ & 4400 & 17 & Normal & Great vessels transposition \\
\hline 10 & $\mathrm{CS}$ & 31 & $7,9,10$ & 1155 & 17 & Normal & Twin, hypoglycemia \\
\hline 11 & $\mathrm{CS}$ & 32 & $10,10,10$ & 1695 & 1 & Normal & Hypoglycemia \\
\hline 12 & $\mathrm{CS}$ & 31 & $8,9,10$ & 1390 & 17 & Plexus cyst & Twin, apneic spells \\
\hline 17 & vaginal & 32 & $7,9,10$ & 2100 & 12 & SEH & $\begin{array}{l}\text { Apneic spells, hypoglycemia, } \\
\text { hypocalcemia }\end{array}$ \\
\hline 18 & CS & 33 & $7,7,7$ & 2290 & 14 & Normal & $\begin{array}{l}\text { HMD, patent ductus arteriosus, } \\
\text { hyperbilirubinemia }\end{array}$ \\
\hline 19 & $\mathrm{CS}$ & 33 & $7,8,10$ & 1140 & 49 & Periventricular echodensities & $\begin{array}{l}\text { HMD, patent ductus arteriosus, apneic } \\
\text { spells, hyperbilirubinemia }\end{array}$ \\
\hline
\end{tabular}

* GA, gestational age (weeks).

$\dagger \mathrm{BW}$, birth weight (grams).

$\ddagger \mathrm{CS}$, cesarean section.

$\S \mathrm{HMD}$, hyaline membrane disease. 
set" reported to baseline (corresponding to 0 change), the chromophore changes before each phase of the study. An increased $\Delta[\mathrm{Hb}$ sum $]$ and $\Delta \mathrm{CBV}$ with respect to the baseline was found in reaction to the auditory stimulus in 13 of the neonates. All of these neonates revealed an increased $\Delta\left[\mathrm{HbO}_{2}\right]$ except for neonate number 5 . On the basis of these patterns, the neonates were arbitrarily considered as responders. Mean $\Delta\left[\mathrm{HbO}_{2}\right]$ values increased from $0.06( \pm 0.41) \mu \mathrm{mol} / \mathrm{L}$ before to $1.08( \pm 1.21)$ during the test. $\Delta[\mathrm{Hb}]$ changes increased from $0.05( \pm 0.35)$ to $0.53( \pm 1.31) \mu \mathrm{mol} / \mathrm{L}$ in the test as did $\Delta\left[\mathrm{Hb}_{\text {sum }}\right]$ from $0.11( \pm 0.34)$ to $1.62( \pm 1.08)$. The comparison between pretest versus test values of chromophores ( $t$ test) in responsive newborns had shown a significant increase of $\Delta\left[\mathrm{HbO}_{2}\right],(p=0.008)$ and $\Delta\left[\mathrm{Hb}_{\text {sum }}\right],(p=0.0001)$ (Fig. 1). The remaining 6 neonates revealed a decreased $\Delta\left[\mathrm{HbO}_{2}\right]$ (average values from $0.07 \pm 1.1$ to $-1.21 \pm 0.35 \mu \mathrm{M}, p=0.007$, $t$ test), $\Delta[\mathrm{Hb}]$ (average values from $-0.27 \pm 0.27$ to $-0.99 \pm$ $0.96 \mu \mathrm{M}, \mathrm{NS}, t$ test ) and $\Delta\left[\mathrm{Hb}_{\text {sum }}\right]$ (average values from -0.2 \pm 1.16 to $-2.2 \pm 0.32 \mu \mathrm{M}, p=0.06, t$ test), because they were considered as nonresponders (Fig. 2). $\Delta\left[\mathrm{Hb}_{\text {sum }}\right]$ enabled the calculation of cerebral blood volume changes in the phases studied. During the stimulation phase there was a significant increase of $\Delta \mathrm{CBV}$ ( $t$ test, $p=0.00006$ ) in the responsive newborns from a mean value of $0.006( \pm 0.02) \mathrm{mL} / 100 \mathrm{~g}$ in the pretest to $0.09( \pm 0.06) \mathrm{mL} / 100 \mathrm{~g}$ during the auditory stimulus (Fig. 3). After the test (Fig. 4) $\triangle \mathrm{CBV}$ decreased to 0.04 $( \pm 0.07) \mathrm{mL} / 100 \mathrm{~g}(p=0.01)$. $\Delta \mathrm{CBV}$ changes in nonresponders presented a decrease during the test phase ( $t$ test, $p=$ 0.04 ) (Fig. 5) and no differences were found when the chromophore mean poststimulus values were compared with the stimulus phase. The same comparison in the responders demonstrated a decreasing $\Delta\left[\mathrm{Hb}_{\text {sum }}\right]$ poststimulation $(p=0.02)$. Hemodynamic response of the subjects who showed increases in $\Delta[\mathrm{Hb}$ sum $]$ and $\Delta\left[\mathrm{HbO}_{2}\right]$ were analyzed to study the $\Delta[\mathrm{Hb}]$ changes. The responsive subjects could be classified into two groups according to $\Delta[\mathrm{Hb}]$ changes: $8 / 13(61.5 \%)$ showed an increase of $\Delta[\mathrm{Hb}]$ (pattern A), while 5/13 (38.4\%) showed a decrease (pattern B) ( $t$ test, $p=0.03$ ). These two patterns did not show differences related to $\Delta\left[\mathrm{HbO}_{2}\right]$ and $\Delta[\mathrm{Hb}$ sum $]$ (Fig. $6)$.

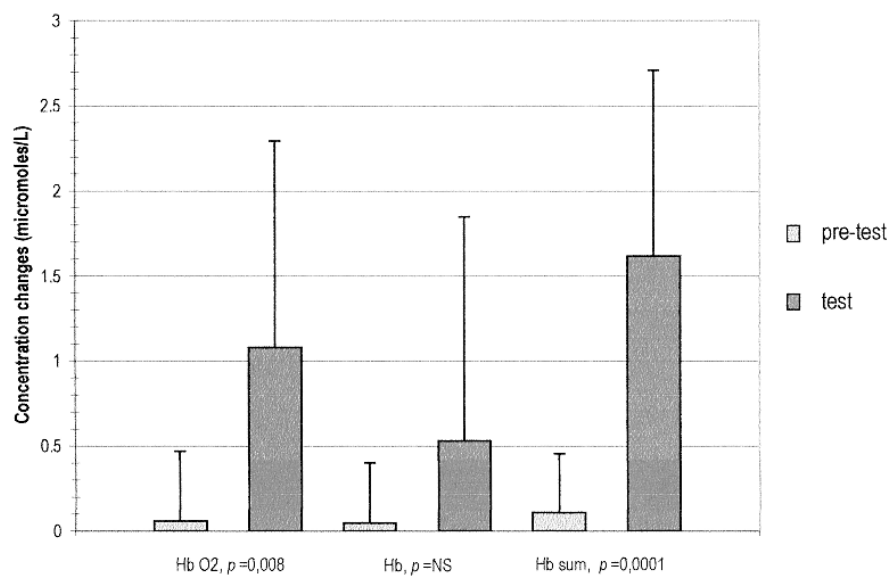

Fig. 1. Comparison between pretest $v s$ test values of chromophores $(t$ test $)$ in responsive newborns.

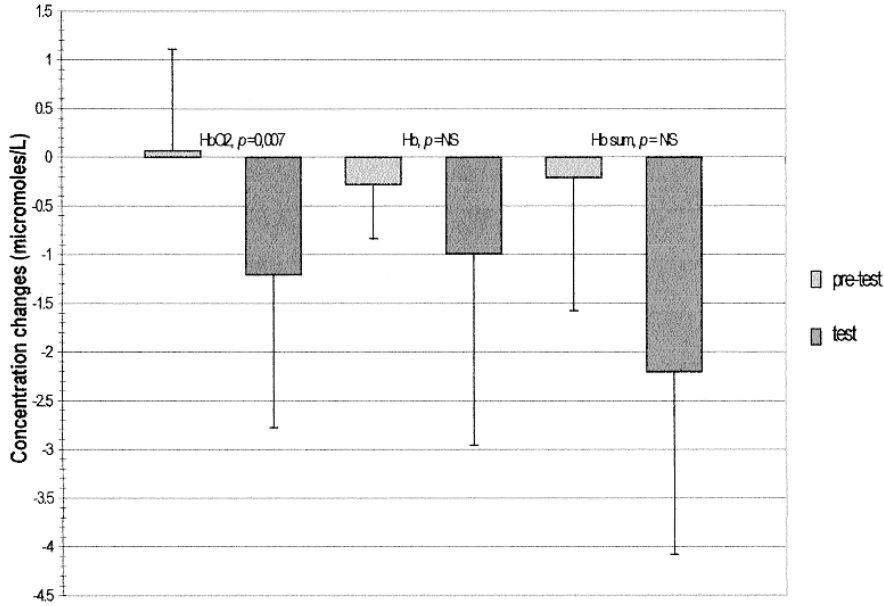

Fig. 2. Comparison between pretest $v s$ test mean values of chromophores $(t$ test) in unresponsive newborns.

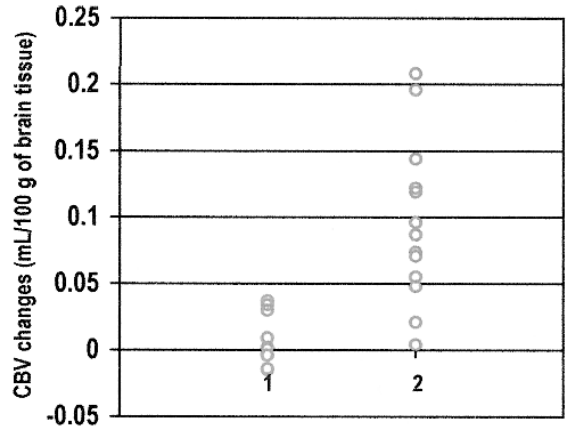

1:CBV pre-test 2:CBV test

Fig. 3. $\mathrm{CBV}$ changes in responsive newborns in relation to the stimulation phase ( $t$ test, $p=0.00006)$.

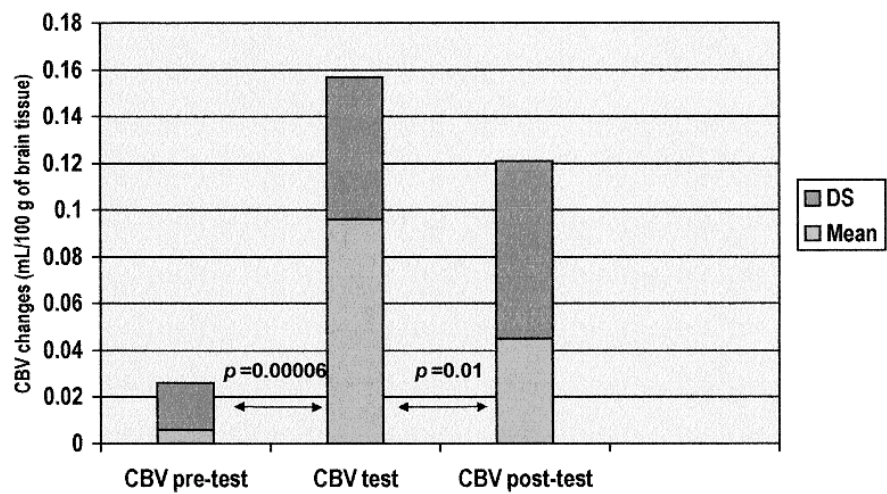

Fig. 4. $\mathrm{CBV}$ changes in responsive newborns ( $t$ test) in relation to the stimulation phase.

Brainstem evoked responses demonstrated that $3 / 13$ of the responders showed abnormal patterns, compared with $1 / 6$ of the nonresponders. The data on a single neonate are presented in Fig. 7: test phase is marked. During stimulation there is an increase in $\left[\mathrm{HbO}_{2}\right]$ and $\left[\mathrm{Hb}_{\text {sum }}\right]$ (red and green lines), which decrease when the stimulus is removed. [Hb] (blue line) decreases during test phase and cytochrome oxidase (yellow line) does not change significantly.

\section{DISCUSSION}

Sensorineural NIRS studies have been performed to measure regional changes in the occipital cortex following visual stim- 


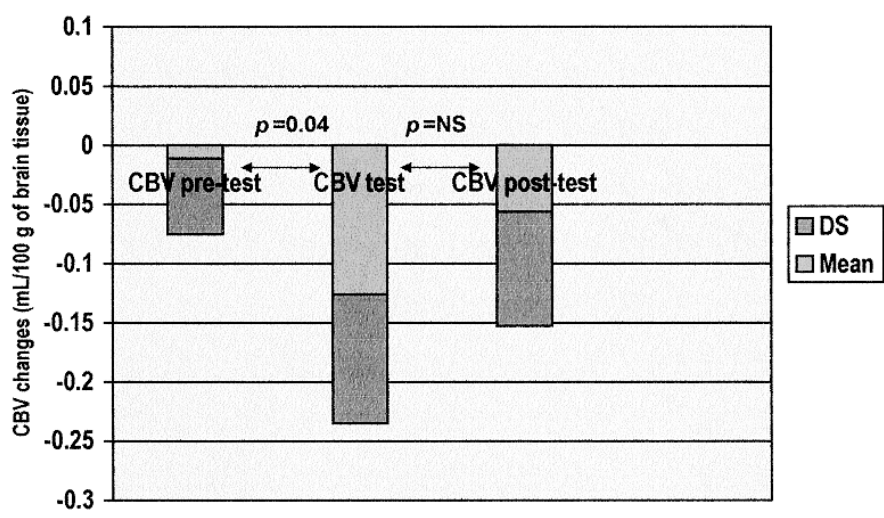

Fig. 5. CBV changes in unresponsive newborns ( $t$ test) in relation to the stimulation phase.

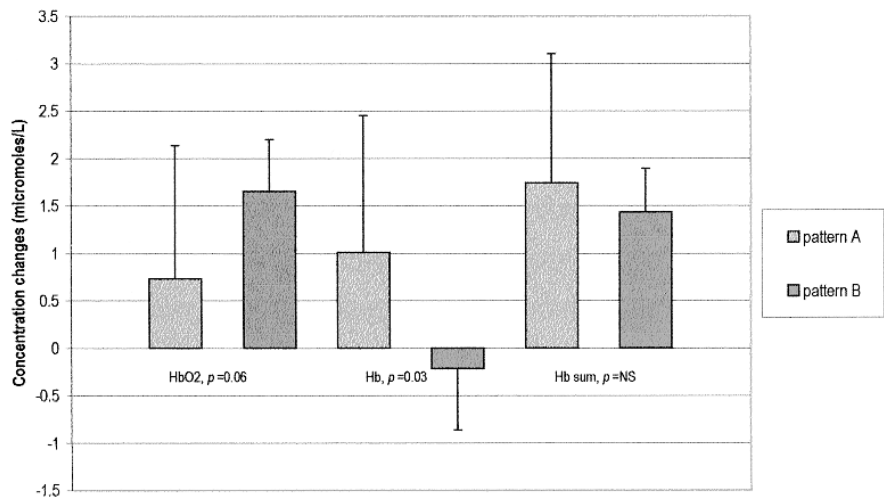

Fig. 6. $t$ Test between the mean values of the subjects with (pattern A, $n=$ 8 ) and without (pattern $\mathrm{B}, n=5$ ) increase of $\mathrm{Hb}$ during the test.

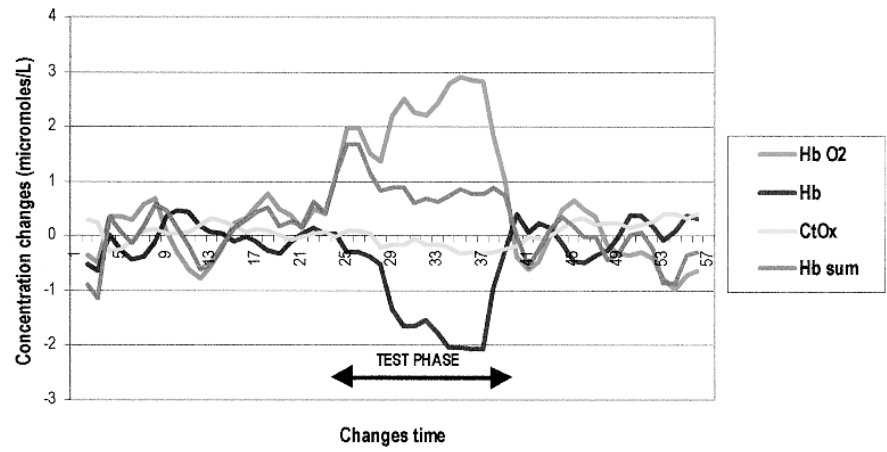

Fig. 7. Tracing of a responsive neonate. Red line indicates the $\Delta\left[\mathrm{HbO}_{2}\right]$ changes; blue line the $\Delta[\mathrm{Hb}]$ as the green the $\Delta\left[\mathrm{Hb}_{\text {sum }}\right]$. Yellow line corresponds to cytochrome oxidase changes. Arrows mark the test phase: an increasing $\Delta\left[\mathrm{HbO}_{2}\right]$ and $\Delta\left[\mathrm{Hb}_{\text {sum }}\right]$ are shown, during the test phase; however, they decrease poststimulation. $\Delta[\mathrm{Hb}]$ decreases during test phase and cytochrome oxidase does not change significantly.

ulation in adults and infants $(7,8)$. Only two adult case studies $(5,9)$ have been published on brain auditory cortex hemodynamics during the hearing function. On the basis of a magnetoencephalographic (MEG) and NIRS study, Ohnishi et al. (9) found the auditory brain area to be about $25 \mathrm{~mm}$ under the scalp. In a dynamic multichannel near-infrared adult study, Hoshi and Tamura (5) reported evoked auditory increases in $\Delta\left[\mathrm{HbO}_{2}\right], \Delta[\mathrm{Hb}], \Delta\left[\mathrm{Hb}_{\text {sum }}\right]$, in a 28 -yr-old man listening to classical music through earphones from a tape-recorder. Saka- tani K et al. (12) had first measured NIRS changes, induced by auditory stimulation, in newborns. They found that frontal lobes show a neuronal response similar to those that have been described in the neonatal visual cortex. Particularly, they found an increase of $\Delta[\mathrm{Hb}]$, associated with increase of the $\Delta\left[\mathrm{HbO}_{2}\right]$ and $\Delta\left[\mathrm{Hb}_{\text {sum }}\right]$, supporting the hypothesis that $\mathrm{O}_{2}$-consumption (blood flow $\times$ arterial-venous oxygen contents) exceeds $\mathrm{O}_{2}$ delivery (blood flow $X$ arterial oxygen content), during neuronal activity in neonates. Adult brain generally presents a reduced concentration of $\Delta[\mathrm{Hb}]$ at the activating cortical area because $\mathrm{O}_{2}$ delivery exceeds $\mathrm{O}_{2}$ consumption (19-23) We studied the auditory response in the temporal area of 19 newborns. The scattering of infrared light in tissue made it impossible to define a precise anatomical border, however. A decline in the NIRS signal has been reported when the optode is misplaced $2 \mathrm{~cm}$ away from the motor cortex (7). This means that an NIRS signal can be recorded with an external band region 1-2 cm wide. The acustic pathways to the cortex are complex. There is an exact correspondence between the cochlea and the acustic area of the cortex (24). Corti's organ has a bilateral representation in the brain and the central pathways enable a distinction between the tonal frequency, intensity and origin of sounds. Auditory brainstem studies show a binaural interaction (25) that our study did not evaluate. In human adults magnetoencephalographic recordings demonstrate processing in the superior temporal plane of the auditory cortex when a novel sound is administered over the acustic environment (26). The auditory association cortex is interconnected with the thalamus. This is a fronto-temporal circuit, which is also connected with the prefrontal cortex to receive unusual auditory stimuli and to enable the elaboration of an integrated auditory memory. Our recordings were made in the temporal region homolateral to the hearing stimulus. In all responsive neonates, except for a neonate who had not increased oxyhemoglobin, $\Delta\left[\mathrm{HbO}_{2}\right]$ and $\Delta\left[\mathrm{Hb}_{\text {sum }}\right]$ increased, and so did $\Delta \mathrm{CBV}$, whereas $\Delta[\mathrm{Hb}]$ increased in $61.5 \%$ of these neonates, similarly to Sakatani's results. Different patterns in evoked cortical responses are probably due to the different phases of the brain development, which are age-dependent. NIRS findings during brain activation in young adults and healthy subjects demonstrated an increase in local $\mathrm{HbO}_{2}$ and corpuscular blood volume, with a decrease in $\mathrm{Hb}$ (4). PET study demonstrates a greater increase in cerebral blood flow than in oxidative metabolism during somatosensory brain stimulation (27). With the aid of PET and MRI studies, in the newborns with no increase in $\Delta[\mathrm{Hb}]$, glucose consumption rather than oxygen extraction can be suggested $(28,29)$. This result is consistent with Meek's findings in the visual stimulation of neonates, which confirm an increasing $\mathrm{CBV}$ with visual stimulation following increases in $\left[\mathrm{HbO}_{2}\right]$ and $[\mathrm{Hb}]$ in most cases, unlike the results of her adult study $(7,8)$. The increase in $\Delta\left[\mathrm{HbO}_{2}\right]$ and $\triangle \mathrm{CBV}$ after the test prompts several considerations. All responsive newborns had a persistent increase in $\triangle \mathrm{CBV}$ and did not return to basal $\triangle \mathrm{CBV}$ values after the stimulation. Electrophysiological data from Alain et al. (30) show evidence of a temporal-prefrontal neocortical pathway for the transient storage of auditory stimuli in adults. This fronto-temporal circuit may detect unusual events in the environment, such as 
our sweep, and justifies the brain work in storing the auditory information after the test. We speculate that there may be a memory in the neonates, or an activation of the temporalparietal circuit for auditory sensory memory. We used the NIRS method to study a cortical temporal response in sleeping and/or waking neonates. Mean $\triangle \mathrm{CBV}$ changed from +0.006 $\mathrm{mL} / 100 \mathrm{~g}$ (pretest) to $+0.09 \mathrm{~mL} / 100 \mathrm{~g}$ (in-test) and +0.04 $\mathrm{mL} / 100 \mathrm{~g}$ (posttest). To date the literature has described an increased $\triangle \mathrm{CBV}$ on visual stimulation $(7,8)$ or hypoxicischemic brain injury $(18,31-33)$ or increasing $\mathrm{P}_{\mathrm{C} 02}$ (15). Pellicer et al. (34) studied NIRS response to an i.v. administration of dexamethasone and found no changes in CBV, but a significant increase in cerebral blood flow. CBV decreases have been observed in relation to the administration of indomethacin versus ibuprofen in preterm infants with PDA and in open endotracheal suctionings or during the withdrawal procedure of exchange transfusions (35-37). Our patients were studied only in the phases of auditory stimulus; no frontal or occipital recordings were feasible. No changes in the redox state of cytochrome oxidase were studied. No changes in $\mathrm{Cu}_{\mathrm{A}}$ redox state were expected because-in animal models with normal cerebral perfusion at least-large-scale changes in the cytochrome oxidase NIR signal are observed only when there is a severely compromised oxygen supply to the tissues (38). Movement artifacts are a frequent problem in studies on alert children, but we filtered the data to cancel the spikes from the tracing. $31.5 \%$ of our neonates did not present any evoked response to the stimulus, the reason why they were arbitrarly considered as nonresponders. However, Münger et al. (39) demonstrated that cerebral oxyhemoglobin and total $\mathrm{Hb}$ concentrations, measured by light-conveying bundles, positioned in the fronto-temporal and, on the same side, in the parietooccipital areas, decreased significantly from quiet to active sleep in healthy newborns. Our percentage of unresponsive neonates may be related more to the change of this physiologic sleeping condition than to a disturbed/abnormal auditory evoked response.

NIRS application is useful for evaluating the temporal region evoked response of the developing brain cortex in neonates, but it is not feasible for screening purposes. When we compare NIRS data with BAEP results, we find no consistency in several cases. Auditory cortical evoked responses show a maturation during the period from $28 \mathrm{wk}$ to $16 \mathrm{yr}$, reflected by a different waveform morphology; the different age of BAEPs evaluation, and also the time of myelogenetic cycles $(40,41)$ may in part justify the inconsistency of the test results in the newborns we studied. In conclusion we consider the application of NIRS to auditory function a valid tool for obtaining more information on brain auditory area metabolism and bloodflow changes. These data confirm that NIRS has a valid role in the mapping of the hemodynamic evoked responses and in the study of oxygen metabolism as well as in brain development in newborns.

Acknowledgments. We thank Dr. Andrea Vianello for technical assistance and critical advice in the pursuit of this study.

\section{REFERENCES}

1. Elwell CE 1995 A Practical Users Guide to Near Infrared Spectroscopy. UCL Reprographics, London, UK, pp 1-25

2. van der Zee P, Cope M, Arridge SR, Essempreis M, Potter LA, Edwards AD, Wyatt JS, Roth SC, Reynolds EOR, Delpy DT 1991 Experimentally measured optical pathlengths for the adults head, calf and forearm and the head of the newborn infant as a function of the interoptode spacing. Adv Exp Med Biol 316:143-153

3. van der Zee P, Arridge SR, Cope M, Delpy DT 1990 The effect of optode positioning on optical pathlength in near-infrared spectroscopy of the brain. Adv Exp Med Biol 277:79-84

4. Villringer A, Planck J, Hock C, Schleinkofer L, Dirnagl U 1993 Near infrared spectroscopy (NIRS): a new tool to study hemodynamic changes during activation of brain function in human adults. Neurosci Lett 154:101-104

5. Hoshi Y, Tamura M 1993 Dynamic multichannel near-infrared optical imaging of human brain activity. J Appl Physiol 75:1842-1846

6. Kato T, Kamei A, Takashima S, Ozaki T 1993 Human visual cortical function during photic stimulation monitoring by means of near-infrared spectroscopy. J Cereb Blood Flow Metab 13.516-520

7. Meek JH, Elwell CE, Khan MJ, Romaya J, Wyatt JS, Delpy DT, Zeki S 1995 Regional changes in cerebral haemodynamics as a result of a visual stimulus measured by near infrared spectroscopy. Proc R Soc Lond B 261:351-356

8. Meek JH, Firbank M, Elwell CE, Aktinson J, Braddick O, Wyatt JS 1998 Regional hemodynamic responses to visual stimulation in awake infants. Pediatr Res 43:840843

9. Ohnishi M, Kusakawa N, Masaki S, Honda K, Hayashi N, Shimada Y, Fujimoto I, Hirao K 1997 Measurement of hemodynamics of auditory cortex using magnetoencephalography and near-infrared spectroscopy. Acta Otolaryngol (Stockh) Suppl 532:129-131

10. Heekeren HR, Kohl M, Obrig H, Wenzel R, von Pannwitz W, Matcher SJ, Dirnagl U, Cooper CE, Villringer A 1999 Noninvasive assessment of changes in cytochrome-c oxidase oxidation in human subjects during visual stimulation. J Cereb Blood Flow Metab 19:592-603

11. Bartocci M, Ruggiero C, Winberg J, Lagercrantz H, Serra G 1999 Percezione di stimoli olfattivi sgradevoli nel neonato in terapia intensiva. Developmental Physiopathology and Clinics, Atti del Congresso Società Italiana di Neonatologia, 14-17 Aprile 1999, Stresa, 9:200-201

12. Sakatani K, Chen S, Lichty W, Zuo H, Wuang Y 1999 Cerebral blood oxygenation changes induced by auditory stimulation in newborns infants measured by near infrared spectroscopy. Early Hum Dev 55:229-236

13. Wyatt JS, Cope M, Delpy DT, Wray S, Reynolds EOR 1986 Quantification of cerebral oxygenation and haemodynamics in sick newborn infants by near infrared spectrophotometry. Lancet 2:1063-1066

14. Benaron DA, Kurth CD, Steven GM, Delivora-Papadopoulos M, Chance B 1995 Transcranial optical path lenght in infants by near-infrared phase-shift spectroscopy. J Clin Monitoring 11:109-117

15. Wyatt JS, Edwards AD, Cope M, Delpy DT, McCormik DC, Potter A, Reynolds EOR 1991 Responses of cerebral blood volume to changes in arterial carbon dioxide tension in term and pre-term infants. Pediatr Res 30:570-573

16. Clarkson MG, Clifton RK, Swain IU Perris EE 1989 Stimulus duration and repetition rate influence newborn's head orientation toward sound. Dev Psychobiol 22:683-705

17. Clarkson MG, Swain IU, Clifton RK, Cohen K 1991 Newborn's head orientation toward trains of brief sounds. J Acoust Soc Am 89:2411-2420

18. van Bel F, Dorrepaal CA, Benders MJNL, Zeeuwe PEM, van de Bor M, Berger HM 1993 Changes in cerebral haemodynamics and oxygenation in the first 24 hours after birth asphyxia. Paediatrics 92:365-372

19. Hock C, Müller-Spahn F, Schuh-Hofer S, Hofmann M, Dirnagl U, Villringer A 1995 Age dependency of changes in cerebral hemoglobin oxygenation during brain activation: a near-infrared spectroscopy study. J Cereb Blood Flow Metab 15:1103-1108

20. Hock C, Villringer K, Müller-Spahn F, Wenzel R, Heekeren H, Schuh-Hofer S, Hofmann M, Minoshima S, Schwaiger M, Dirnagl U, Villringer A 1997 Decrease in parietal cerebral hemoglobin oxygenation during performance of a verbal fluency task in patients with Alzheimer's disease monitored by means of near-infrared spectroscopy (NIRS)-correlation with simoultaneous rCBF-PET measurements. Brain Res 755:293-303

21. Hoshi Y, Onoe H, Watanabe Y, Anderson J, Bergström M, Lilja A, Längström B, Tamura M 1994 Non-syncronous behavior of neuronal activity, oxidative metabolism and blood supply during mental task in man. Neurosci Lett 172:129-33

22. Sakatani K, Xie Y, Lichty W, Li S, Zuo H 1998 Language-activated cerebral blood flow oxygenation and hemodynamic changes of the left prefrontal cortex in poststroke aphasic patients: a near infrared spectroscopy study. Stroke 29:1299-1304

23. Villringer K, Minoshima S, Hock C, Obrig H, Ziegler S, Dirnagl U, Schwaiger M, Villringer A 1997 Assessment of local brain activation. A simultaneous PET and near-infrared spectroscopy study. Adv Exp Med Biol 413:149-153

24. Netter FH 1977 1-Nervous System. The CIBA Collection of Medical Illustrations. New York

25. Cone-Wesson B, Ma E, Fowler CG 1997 Effect of stimulus level and frequency on ABR and MLR binaural interaction in human neonates. Hear Res 106:163-178

26. Alho K, Winkler I, Escera C, Huotilainen M, Virtanen J, Jääskeläinen IP, Pekkonen E, Ilmoniemi R 1998 Processing of novel sounds and frequency changes in the human auditory cortex: magnetoencephalographic recordings. Psychophysiology 35:211224

27. Fox PT, Raichle ME 1986 Focal physiological uncoupling of cerebral blood flow and oxidative metabolism during somatosensory stimulation in human subjects. Proc Natl Acad Sci USA 83:1140-1144 
28. Ogawa S, Tank DW, Menon R, Ellerman JM, Kim SG, Merkle H, Ugurbil K 1992 Intrinsic signal changes accompanying sensory stimulation: functional brain mapping with magnetic resonance imaging. Proc Natl Acad Sci USA 89:59515955

29. Prichard J, Rothman D, Novotny E, Petroff O, Kuwabara T, Avison M, Howseman A, Hanstock C, Shulman R 1991 Lactate rise detected by 1H NMR in human visual cortex during physiologic stimulation. Proc Natl Acad Sci USA 88:58295831

30. Alain C, Woods DL, Knight RT 1998 A distributed cortical network for auditory sensory memory in humans. Brain Res 812:23-37

31. Wyatt JS, Cope M, Delpy DT, Richardson CE, Edwards AD, Wray S, Reynolds EOR 1990 Quantitation of cerebral blood volume in human infants by near-infrared spectroscopy. J Apply Physiol 68:1086-1091

32. Wyatt JS 1997 Cerebral oxygenation and haemodynamics in the foetus and newborn infant. Phil Trans R Soc Lond B 352:697-700

33. Meek JH, Elwell CE, McCormick C, Edwards AD, Townsend JP, Stewaet AL, Wyat JS 1999 Abnormal cerebral haemodynamics in perinatally asphyxiated neonates related to outcome. Arch Dis Child Fetal Neonatal Ed 81:F110-F115

34. Pellicer A, Gaya' F, Stiris TA, Quero J, Cabanas F 1998 Cerebral haemodynamics in preterm infants after exposure to dexamethasone. Arch Dis Child Fetal Neonatal Ed 79:F123-F128
35. Mosca F, Bray M, Lattanzio M, Fumagalli M, Tosetto C 1997 Comparative evaluation of the effects of indomethacin and ibuprofen on cerebral perfusion and oxygenation in preterm infants with patent ductus arteriosus. J Pediatr 131:549-554

36. Mosca F, Colnaghi M, Lattanzio M, Bray M, Pugliese S, Fumagalli M 1997 Closed versus open endotracheal suctioning in preterm infants: effects on cerebral oxygenation and blood volume. Biol Neonate 72:9-14

37. van de Bor M, Benders MJNL, Dorrepaal CA, van Bel F, Brand R 1994 Cerebral blood volume changes during exchange transfusions in infants born at or near term. J Pediatr 125:617-621

38. Cooper CE, Cope M, Quaresima V, Ferrari M, Nemoto E, Springett R, Matcher S, Amess P, Penrice J, Tyszczuk L, Wyatt J, Delpy DT 1997 Measurement of cytochrome oxidase redox state by near infrared spectroscopy. In: Villringer A, Dirnagl $\mathrm{U}$ (eds) Optical Imaging of Brain function and Metabolism II.Plenum Press, New York, pp 63-73

39. Münger DM, Bucher HU, Gabriel D 1998 Sleep state changes associated with cerebral blood volume changes in healthy term newborn infants. Early Hum Dev 52:27-42

40. Pasman JW, Rotteveel JJ, Maassen B, Visco YM 1999 The maturation of auditory cortical evoked responses between (preterm) birth and 14 years of age. Eur J Pediatr Neurol 3:79-82

41. Volpe JJ 1995 Neurology of the Newborn. WB Saunders Company, pp 79-81 